\title{
The nasopalatine canal and its relationship with the maxillary central incisors: a
}

\section{cone-beam computed tomography study}

\author{
Canal nasopalatino e sua relação com os incisivos centrais superiores: estudo com tomografia \\ computadorizada de feixe cônico
}

Canal nasopalatino y su relación con los incisivos centrales superiores: estudio mediante tomografía computarizada de haz cónico

\begin{abstract}
Objective: To evaluate the dimensions of the nasopalatine canal (NPC) and its relationship with the maxillary central incisors (MCI) using cone-beam computed tomography (CBCT) and to determine variations in the NPC in relation to age and gender. Methods: CBCT scans from 333 patients $(67 \%$ female; $35.9 \pm 14.6$ years) were included. The CBCT scan was analyzed to determine the length and diameter of the NPC, the distance between the NPC and the MCI, and to evaluate the morphology of the NPC. The data were analyzed using the independent Student's t-test, the MannWhitney and Kruskal-Wallis tests, and Dunn's post-test $(\mathrm{p}<0.05)$. Results: The average diameter and length of the NPC were $2.92 \pm 0.91 \mathrm{~mm}$ and $12.67 \pm 3.32 \mathrm{~mm}$, respectively. The minimum and maximum distance between the MCI and the NPC were $0.78 \pm 0.42 \mathrm{~mm}$ and $2.56 \pm 1.38 \mathrm{~mm}$, respectively. The NPC of male patients was greater in length compared with the female patients $(\mathrm{p}<0.05)$. The majority presented a funnel-like morphology $(34.1 \%)$, followed by a cylindrical morphology $(27.5 \%)$. Conclusions: There was variability in the dimensions of the NPC and its relationship with the MCI, which was influenced by gender and age.
\end{abstract}

Keywords: Cone-beam computed tomography; Diagnosis differential; Incisor.

\section{Resumo}

Objetivo: Avaliar as dimensões do canal nasopalatino (CNP) e sua relação com os incisivos centrais superiores (ICS) usando tomografia computadoriza de feixe cônico (TCFC) e determinar as variações do CNP de acordo com a idade e o gênero. Métodos: Imagens de TCFC de 333 pacientes (67\% mulheres; 35,9 \pm 14.6 anos) foram incluídas. As imagens de TCFC foram analisadas para determinar o comprimento e o diâmetro do CNP, a distância entre o CNP e os ICS, e para avaliar a morfologia do CNP. Os dados foram analisados pelos Testes T de Student, Mann-Whitney e Kruskal-Wallis, e pós-teste de Dunn $(\mathrm{p}<0,05)$. Resultados: As médias do diâmetro e do comprimento do CNP foram $2,92 \pm 0,91 \mathrm{~mm}$ e 12,67 $\pm 3,32 \mathrm{~mm}$, respectivamente. As distâncias mínima e máxima entre os ICS e o CNP foram $0,78 \pm 0,42 \mathrm{~mm}$ e $2,56 \pm 1,38 \mathrm{~mm}$, respectivamente. O comprimento do CNP foi maior entre os homens quando 
comparado as mulheres $(\mathrm{p}<0,05)$. A morfologia mais comum foi a afunilada $(34,1 \%)$, seguida pela cilíndrica $(27,5 \%)$. Conclusões: Existe variabilidade nas dimensões do CNP e em sua relação com os ICS, as quais foram influenciadas pelo gênero e pela idade.

Palavras-chave: Diagnóstico diferencial; Incisivo; Tomografia computadorizada de feixe cônico.

\begin{abstract}
Resumen
Objetivo: Evaluar las dimensiones del canal nasopalatino (CNP) y su relación con los incisivos centrales superiores (ICS) mediante tomografía computarizada de haz cónico (TCHC) y determinar las variaciones del CNP según edad y sexo. Métodos: Se incluyeron imágenes de TCHC de 333 pacientes (67\% mujeres; 35,9 \pm 14,6 años). Se analizaron las imágenes de TCHC para determinar la longitud y el diámetro del CNP, la distancia entre el CNP y los ICS y evaluar la morfología del CNP. Los datos se analizaron mediante las pruebas T de Student, Mann-Whitney y KruskalWallis, y la prueba posterior de Dunn ( $\mathrm{p}<0,05)$. Resultados: El diámetro y la longitud promedios del CNP fueron 2,92 $\pm 0,91 \mathrm{~mm}$ y $12,67 \pm 3,32 \mathrm{~mm}$, respectivamente. Las distancias mínima y máxima entre el ICS y el CNP fueron de $0,78 \pm 0,42 \mathrm{~mm}$ y $2,56 \pm 1,38 \mathrm{~mm}$, respectivamente. La longitud del CNP fue mayor entre los hombres en comparación con las mujeres ( $\mathrm{p}<0,05)$. La morfología más común fue en embudo $(34,1 \%$ ), seguida de cilíndrica $(27,5 \%)$. Conclusiones: Existe variabilidad en las dimensiones del CNP y en su relación con los ICS, las cuales fueron influenciadas por el sexo y la edad.
\end{abstract}

Palabras clave: Diagnóstico diferencial; Incisivo; Tomografía computarizada de haz cónico.

\title{
1. Introduction
}

The anterior region of the maxilla is the most relevant in dental rehabilitation due to high aesthetic, functional and phonetic demand (Kim, et al., 2020). Moreover, it is the region that is most affected by dental and maxillofacial traumas (Etoz \& Sisman, 2014), where most granulomas and periapical cysts occur (Lo Muzio, et al., 2017) and with a higher prevalence in apical surgeries (Creasy, et al., 2009).

The diagnosis and planning of dental procedures in the anterior region of the maxilla should account for possible anatomical variations (Asaumi, et al., 2010), particularly the nasopalatine canal (NPC) and its relationship with the maxillary central incisors (MCI), avoiding damage to vessels and nerves during anesthesia, implant positioning errors, osseointegration failures, and transient sensory alterations, which occur when the NPC is perforated, injuring the adjacent neural system (Friedrich, et al., 2015). Additionally, radiolucent/hypodense images in the anterior region of the maxilla may be associated with non-odontogenic pathological processes, such as the nasopalatine duct cyst (NPDC) which, as a function of the size and radiographic projection used, can be confused with periapical pathological processes of endodontic origin (Suter, et al., 2011). Furthermore, the proximity of the NPC to the MCI is relevant since an inflammatory process of endodontic or periodontal origin in these teeth can achieve, through inflammatory cytokines of the periradicular lesion or periodontal strain, the epithelial remains of the NPC and may play a role in the pathogenesis of NPDC (Tsuneki, et al., 2013; Suter, et al., 2016).

In this context, the use of cone-beam computed tomography (CBCT) provides high-resolution images that facilitate a three-dimensional evaluation of the morphology of the NPC, its variability, and its relationship with adjacent anatomical structures. According to the European Society of Endodontics (Patel, et al., 2019), the CBCT examination presents specific indications during the management of complex cases. CBCT is the most common method used in the diagnosis of pathological processes of nonspecific symptomatology involving maxillomandibular bone tissues because it facilitates the identification of early-stage lesions in the periradicular region. Moreover, it provides a differential diagnosis between pathological odontogenic processes (particularly of endodontic origin) and non-odontogenic processes (Lo Muzio, et al., 2017).

Previous studies (Etoz \& Sisman, 2014; Fernández-Alonso, et al., 2015; Friedrich, et al., 2015; Jain, et al. 2017; Thakur, et al., 2013); that evaluated the dimensions of the NPC in CBCT images demonstrated great variability regarding the diameter and length of the canal. This may have been due to the population studied, the sample size, and the characterization. Only two studies evaluated the relationship between the NPC and MCI (Chatriyanuyoke, et al., 2012; Friedrich, et al., 2015), and no studies included the Brazilian population. Thus, the present study aimed to assess the dimension and morphology of the 
NPC among Brazilian patients and examine its relationship with the MCI through CBCT images. Moreover, the study aimed to evaluate possible variations between the genders and ages. The null hypothesis tested was (a) there was a difference between genders and (b) age influenced the dimensions and morphology of the NPC and its relationship with the MCI.

\section{Methodology}

Study design and population

This observational study was designed as a retrospective analysis of CBCT images obtained between 2012 and 2016 in the Department of Pathology and Oral diagnosis of the Faculty of Dentistry of the Federal University of Rio de Janeiro. All patient identifiers were removed from the image files, and the retrospective study was deemed exempt from review by the ethical committee of the Local Research Ethics Committee (n. 2.494.313). The study was performed according to the Declaration of Helsinki.

CBCT had been advised for various diagnostic purposes (among others, dental implants, impacted teeth and oral pathology). The inclusion criteria used were examinations from patients older than 18 years of age; presence of two intact MCI or without coronary restorations that would compromise the length of the MCI and complete visualization of the NPC. We excluded examinations that demonstrated the presence of pathological processes or supernumerary teeth in the evaluated region and the presence of metallic or movement artifacts that could interfere with the adequate evaluation of the images. The initial sample consisted of 1654 CBCT examinations that included the maxilla. Of these, 1321 did not meet the selection criteria and were eliminated from the data set, resulting in a final sample comprising 333 patients. The variables gender and age were also collected. Age was subdivided into three age groups: 18 to 39 years; 40 to 59 years and 60 to 74 years.

CBCT analysis

All the evaluated exams were acquired by a single CBCT scanner, Kodak K9500 (Carestream Health, NY, USA), under the same acquisition parameters: $10 \mathrm{mAs}, 90 \mathrm{kVp}$, exposure time of 10.8 seconds, a field of view of $9.5 \mathrm{x} 15 \mathrm{~cm}$ and isotropic voxel of $0.2 \mathrm{~mm}$.

The analyses were performed using dedicated computer software (CS 3D Imaging. Carestream Health, NY, USA). All assessments were performed by a single, duly trained examiner duly with experience in tomographic image assessment. The examiner's training was performed as follows: initially, 30 examinations were evaluated, and after 30 days, under the same conditions, they were re-evaluated to establish the degree of intra-rate concordance (Kappa $=0.90)$.

The following analyses and measurements were performed in the multiplanar reconstructions (sagittal, axial and coronal).

a) NPC, incisive foramen $(I F)$ and foramina of Stenson $(S F)$ : coronal reconstruction was used to obtain these measurements, and correction of the angulation was performed from the sagittal reconstruction. Initially, the sagittal plane was selected to represent the most central point of the NPC, with the cortical equidistant. The selection of the reference point was made with a three-dimensional navigation tool that simultaneously shows the position in the axial and coronal planes, placing the orientation line of the coronal reconstruction in the sagittal plane, exactly at the centre of the NPC, maintaining parallelism between the cortical channel (Figure 1A). With the coronal plane defined, the diameter of the SF was measured at the most superior point corresponding to the opening of the NPC, where the multiple SF, when present, are in a single opening (Figure 1B). In addition to the diameter, using the axial plane as a reference, a count of the number of SF present at the upper extremity of the NPC was performed (Figure 2). Then, the diameter of the IF was measured at the lowest point corresponding to the opening of the NPC (Figure 1C). Still using the coronal plane as a reference, the length of the NPC was measured, linking the reference points of the IF and SF at the most superior and inferior point, respectively, corresponding to the opening of the NPC 
(Figure 1D). To define the diameter of the NPC, the mean of the three diameters of the NPC was used, which corresponds to the diameters of the IF, the SF and the diameter of half the length of the NPC.

Figure 1. Diameter of the Foramina of Stenson (B); diameter of the incisive foramen (C); length of the NPC (D). Sagittal slice (A); Coronal slice (B); (C); (D); Selection of coronal slice from the sagittal slice (A).
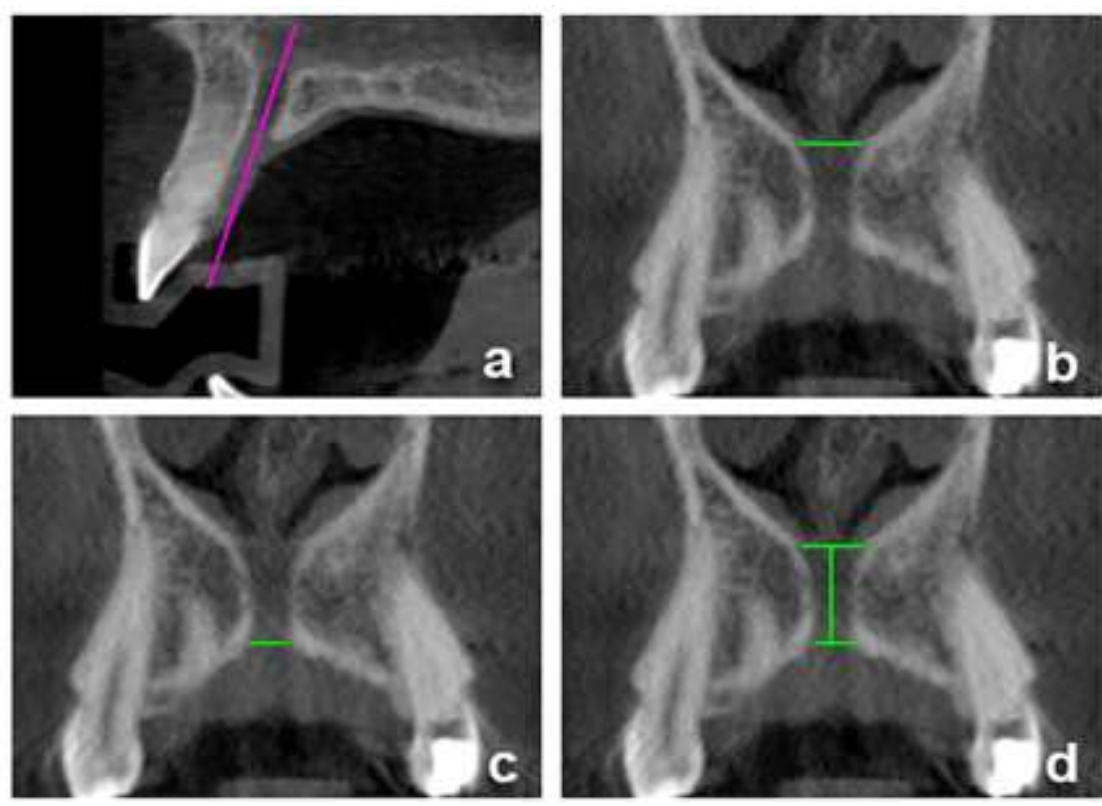

Source: Authors.

Figure 2. Number of the Foramina of Stenson: one (A); two (B); three (C); four (D). Axial Slice (A); (B); (C); (D).
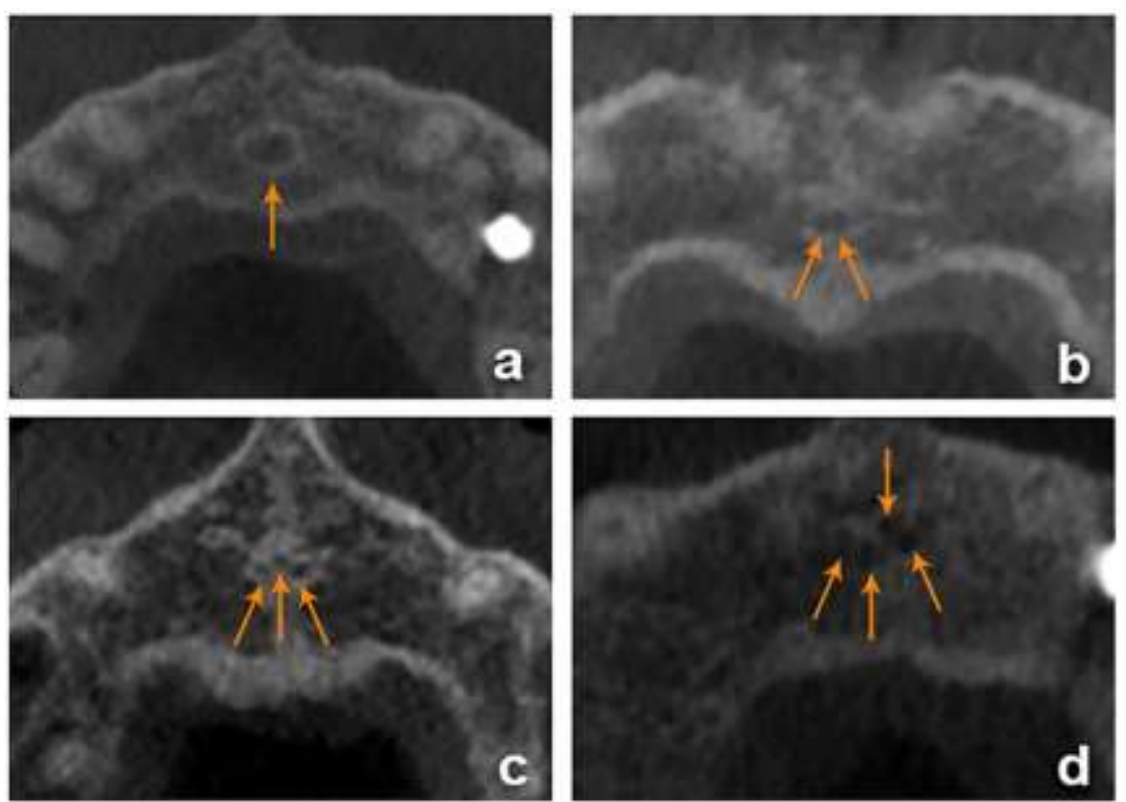

Source: Authors.

b) MCI length and relationship between NPC and MCI: the two ICS (Fernández-Alonso, et al., 2015; Mraiwa, et al., 2004) were measured. The sagittal plane was inspected to determine the image that showed the entire length of the teeth. The 
most representative central reconstruction was selected, having as reference the long axis of the teeth, where the vestibular and palatal faces were equidistant. To determine the MCI lengths, the linear measurement tool of the program was used, where the total length was measured in millimetres, both on the right and left sides. The distance in millimetres between the root of the MCI and the NPC was determined using the program measurement tool, where the measurement extended from the NPC to half the root length, which was determined by the distance between the amelo-cementary junction and the apex root. The axial orientation line was positioned exactly at half the root length. With the axial plane defined, the minimum distance of the NPC was measured at half the root length of the MCI (Figures 3A, 3B). The distance between the apex of the MCI and the NPC was determined by the minimum distance, in millimetres, from the NPC to the root apex. The axial orientation line was positioned exactly in the apical portion of the root, and the axial plane defined was measured as the minimum distance from the NPC to the beginning of the root apex (Figure 3C), (Figure 3D).

Figure 3. Distance from the NPC to the midroot level of the maxillary central incisor (B) and Distance from the NPC to the apex level of the maxillary central incisor (D). Sagittal slice (A); (C); Axial Slice (B) and (D).
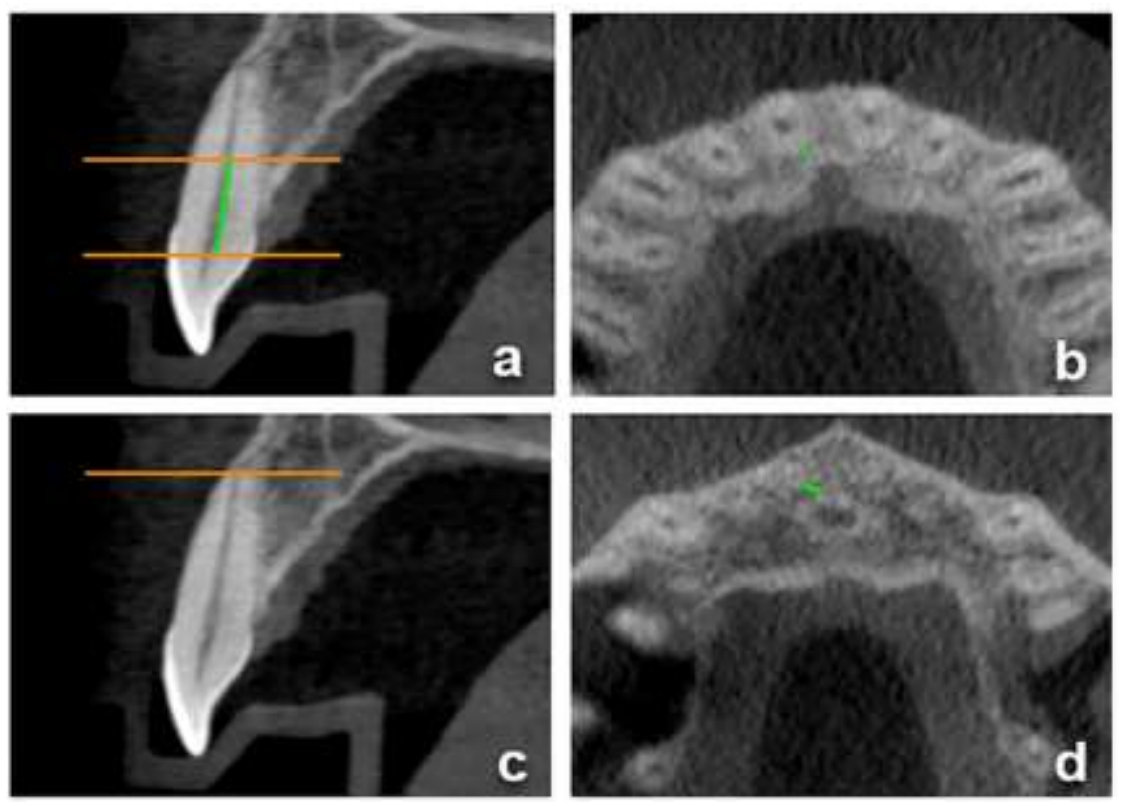

Source: Authors.

c) Morphology of the NPC: a qualitative analysis of the anatomical variants of the NPC was performed, using as a reference the sagittal plane, from the navigation through the entire volume of the teeth examined. The classification of the NPC was based on the criteria established by Mardinger et al. (2008) i.e., 1 - cylindrical; 2 - funnel; 3 - hourglass; and 4 - bananashaped (Figure 4). 
Figure 4. NPC Morphology: (A) Cylindrical; (B) funnel-like; (C) Hourglass-like; (D) Banana-like. Sagittal slice (A); (B); (C); (D).
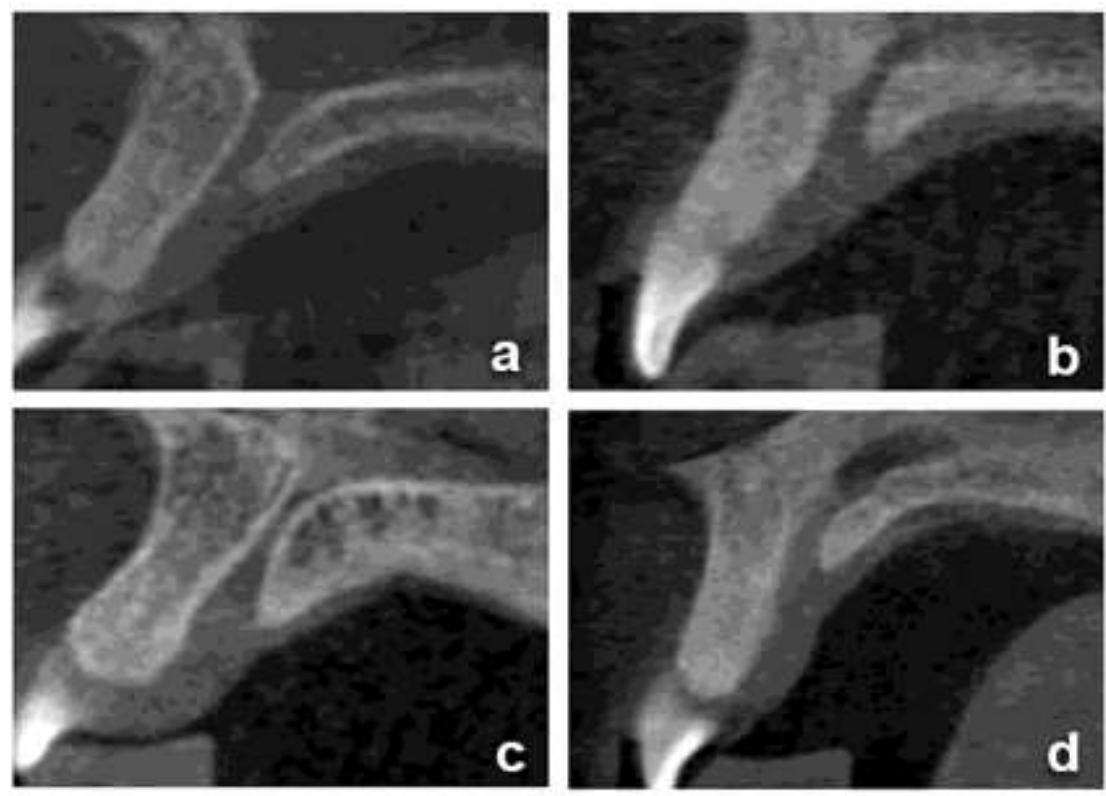

Source: Authors.

\section{Statistical analysis}

Data were analysed descriptively using the program SPSS (Statistical Package for Social Sciences), version 23 (SPSS Inc., Chicago, IL, USA). The normality of the data was analysed by the Shapiro-Wilk test; the variables had a non-normal distribution $(\mathrm{P}<0.05)$. To explore differences between the genders and the characteristics of the NPC and related variables the Mann-Whitney test was used, while to evaluate differences between the age groups and the characteristics of the NPC and related variables the Kruskal-Wallis test followed by Dunn's post-test was used. The significance level was $\mathrm{p}<0.05$. The chisquare test was used to evaluate differences between genders and age groups regarding the morphology of the NPC and the number of SF.

\section{Results}

The study included 333 patients (67\% female). The mean age was $35.9 \pm 14.6$ years (18-74 years), and the distribution according to age range was 216 patients (64.9\%) between 18 and 39 years, 91 patients (27.3\%) between 40 and 59 years, and 26 patients (7.8\%) between 60 and 74 years. The anatomical characteristics of the NPC and related structures are presented in Table 1. 
Research, Society and Development, v. 10, n. 15, e351101522978, 2021

(CC BY 4.0) | ISSN 2525-3409 | DOI: http://dx.doi.org/10.33448/rsd-v10i15.22978

Table 1. Nasopalatine canal (NPC) dimensions (mm) and related anatomical structures.

\begin{tabular}{|c|c|c|}
\hline \multirow{2}{*}{ Anatomical Structeres } & \multicolumn{2}{|c|}{ Dimensions } \\
\hline & Mean \pm SD* & Minimum - Maximum \\
\hline NPC diameter & $2.92 \pm 0.91$ & $0.50-5.60$ \\
\hline NPC length & $12.67 \pm 3.32$ & $5.60-24.30$ \\
\hline Incisive foramen diameter & $3.49 \pm 1.24$ & $0.60-7.60$ \\
\hline Foramina of Stenson diameter & $2.89 \pm 1.19$ & $0.60-7.60$ \\
\hline Length right $\mathrm{MCI}^{* *}$ & $23.7 \pm 2.02$ & $17.80-29.80$ \\
\hline Length left MCI & $23.8 \pm 1.94$ & $18.10-29.60$ \\
\hline $\begin{array}{c}\text { Distance from the NPC to the midroot } \\
\text { level of the right MCI }\end{array}$ & $0.85 \pm 0.41$ & $0.20-5.40$ \\
\hline $\begin{array}{c}\text { Distance from the NPC to the apex level } \\
\text { of the right MCI }\end{array}$ & $2.82 \pm 1.37$ & $0.20-6.50$ \\
\hline $\begin{array}{c}\text { Distance from the NPC to the midroot } \\
\text { level of the left MCI }\end{array}$ & $0.78 \pm 0.42$ & $0.20-5.10$ \\
\hline $\begin{array}{c}\text { Distance from the NPC to the apex level } \\
\text { of the left MCI }\end{array}$ & $2.56 \pm 1.38$ & $0.10-6.60$ \\
\hline
\end{tabular}

*SD standard deviation; **Maxillary central incisor (MCI). Source: Authors.

The distribution of the anatomical characteristics of the NPC and related structures according to gender are presented in Table 2. Statistically, the length of the NPC ( $p<0.0001)$, tooth 11 ( $p<0.0001)$, and tooth 21 (p < 0.0001) were greater in males. However, no statistically significant differences were observed between genders for the NPC diameter, IF diameter, SF diameter, or the distance between the apex and half of the root of tooth 11 and tooth 21 up to the NPC. 
Table 2. Nasopalatine canal (NPC) dimensions ( $\mathrm{mm}$ ) and anatomical structures related according to gender.

\begin{tabular}{|c|c|c|c|}
\hline \multirow{2}{*}{ Anatomical structures } & \multicolumn{2}{|c|}{ Mean $(\mathrm{mm}) \pm \mathrm{SD}^{*}$} & \multirow{2}{*}{$\mathrm{P}$ value } \\
\hline & Men & Women & \\
\hline NPC diameter & $2.87 \pm 0.91$ & $2.95 \pm 0.91$ & 0.34 \\
\hline NPC length & $13.52 \pm 3.09$ & $12.25 \pm 3.36$ & $0.00 * * *$ \\
\hline Incisive foramen diameter & $3.42 \pm 1.14$ & $3.52 \pm 1.28$ & 0.66 \\
\hline Foramina of Stenson diameter & $2.87 \pm 1.26$ & $2.90 \pm 1.16$ & 0.59 \\
\hline Length right $\mathrm{MCI}^{* *}$ & $24.77 \pm 2.01$ & $23.20 \pm 1.82$ & $0.00 * * *$ \\
\hline Length left MCI & $24.73 \pm 1.97$ & $23.37 \pm 1.76$ & $0.00 * * *$ \\
\hline $\begin{array}{c}\text { Distance from the NPC to the midroot } \\
\text { level of the right MCI }\end{array}$ & $0.95 \pm 0.72$ & $0.80 \pm 0.70$ & 0.50 \\
\hline $\begin{array}{l}\text { Distance from the NPC to the apex level } \\
\text { of the right MCI }\end{array}$ & $2.95 \pm 1.32$ & $2.77 \pm 1.40$ & 0.23 \\
\hline $\begin{array}{l}\text { Distance from the NPC to the midroot } \\
\text { level of the left MCI }\end{array}$ & $0.90 \pm 0.80$ & $0.73 \pm 0.67$ & 0.23 \\
\hline $\begin{array}{l}\text { Distance from the NPC to the apex level } \\
\text { of the left MCI }\end{array}$ & $2.59 \pm 1.19$ & $2.54 \pm 1.47$ & 0.37 \\
\hline
\end{tabular}

*SD standard deviation; ** Maxillary central incisor (MCI); ***Mann Whitney Test $\mathrm{p}<0.05$. Source: Authors.

The distribution of the anatomical characteristics of the NPC and related structures according to age group are presented in Table 3 . 
Table 3. NPC dimensions (mm) and anatomical structures related according to age groups.

\begin{tabular}{|c|c|c|c|c|}
\hline \multirow{3}{*}{ Anatomical structures } & \multicolumn{3}{|c|}{ Age groups (years) } & \multirow{3}{*}{$P$ value } \\
\hline & $18-39$ & $40-59$ & $60-75$ & \\
\hline & \multicolumn{3}{|c|}{ Mean $(\mathrm{mm}) \pm \mathrm{SD}$} & \\
\hline NPC diameter & $2.86 \pm 0.89$ & $3.11 \pm 0.94$ & $2.80 \pm 0.93$ & 0.34 \\
\hline NPC length & $12.52 \pm 3.37$ & $12.78 \pm 3.30$ & $13.54 \pm 2.97$ & 0.22 \\
\hline Incisive foramen diameter & $3.40 \pm 1.25$ & $3.66 \pm 1.23$ & $3.56 \pm 1.13$ & 0.66 \\
\hline Foramina of Stenson diameter & $2.83 \pm 1.19$ & $3.10 \pm 1.15$ & $2.68 \pm 1.30$ & 0.06 \\
\hline Length right $\mathrm{MCI}^{* * *}$ & $23.96 \pm 1.99$ & $23.34 \pm 2.05$ & $23.0 \pm 1.87$ & $0.02 * *$ \\
\hline Length left MCI & $24.08 \pm 1.83$ & $23.43 \pm 2.05$ & $23.08 \pm 2.05$ & $0.02 * *$ \\
\hline $\begin{array}{l}\text { Distance from the NPC to the } \\
\text { midroot level of the right MCI }\end{array}$ & $0.82 \pm 0.74$ & $0.88 \pm 0.66$ & $0.95 \pm 0.56$ & 0.08 \\
\hline $\begin{array}{l}\text { Distance from the NPC to the } \\
\text { apex level of the right MCI }\end{array}$ & $2.70 \pm 1.37$ & $2.96 \pm 1.38$ & $3.35 \pm 1.24$ & 0.06 \\
\hline $\begin{array}{l}\text { Distance from the NPC to the } \\
\text { midroot level of the left MCI }\end{array}$ & $0.78 \pm 0.77$ & $0.81 \pm 0.65$ & $0.76 \pm 0.45$ & 0.14 \\
\hline $\begin{array}{l}\text { Distance from the NPC to the } \\
\text { apex level of the left MCI }\end{array}$ & $2.46 \pm 1.32$ & $2.67 \pm 1.55$ & $2.97 \pm 1.23$ & 0.13 \\
\hline
\end{tabular}

Source: Authors.

Statistically significant differences were observed between the lengths of tooth 11 and tooth 21 according to the age group. Tooth $11(\mathrm{p}<0.05)$ and tooth $21(\mathrm{p}<0.05)$ were significantly longer in the 18-39 years age group compared with the 40-59 years and 60-74 years age groups. No significant difference was observed between the 40-59 years and 60-74 years age groups $(p>0.05)$. No statistically significant differences were observed between the age groups regarding the length $(p>$ $0.05)$ and diameter of the NPC ( $p>0.05)$, the diameter of the IF ( $p>0.05)$ and SF ( $p>0.05)$, and distance between the apices of tooth $11(\mathrm{p}>0.05$ and tooth $21(\mathrm{p}>0.05)$ and the NPC.

Most patients presented an NPC morphology in the funnel form (34.1\%), followed by cylindrical (27.5\%), hourglass (25.1\%), and banana morphologies (13.3\%). No significant difference was observed between the genders regarding the morphology of the NPC ( $p>0.05$ ). The funnel shape and the cylindrical shape of the NPC were more common in the 60-74 years $(\mathrm{p}=0.026)$ and $18-39$ years $(\mathrm{p}=0.022)$ age groups. In the $40-59$ years age group, most patients presented an NPC in the funnel form.

Most of the patients presented one SF (41.7\%), followed by two (32.6\%), three (23.1\%), and four (2.4\%) SF. The presence of one or two SF was significantly higher in females $(\mathrm{p}=0.017)$. Conversely, no statistically significant differences were observed between the age groups regarding the number of SF.

\section{Discussion}

This study evaluated the dimensions and morphology of the NPC and its relationship with the MCI through CBCT images. The mean length of the NPC was similar to that observed in previous studies (Etoz \& Sisman, 2014; FernándezAlonso, et al., 2014) and was within the reported mean variation range of 9.04 and $14.10 \mathrm{~mm}$ (Acar \& Kamburoğlu 2014; 
Bornstein, et al., 2011; Friedrich, et al., 2015; Jain, et al., 2017; Özçakır-Tomruk, et al., 2016; Panjnoush, et al., 2016). The mean diameter of the SF was similar to that observed in a previous study (Özçakır-Tomruk, et al., 2016); however, it differed from that observed in other studies that demonstrated a larger mean diameter (Etoz \& Sisman, 2014; Panjnoush, et al., 2016). The mean diameter of the IF was similar (Acar \& Kamburoğlu 2014; Etoz \& Sisman, 2014) or did not show significant discrepancies compared with that recorded in previous studies (Bornstein, et al., 2011; Fernández-Alonso, et al., 2014; Friedrich, et al., 2015; Jain, et al., 2017; Özçakır-Tomruk, et al., 2016).

In this study, no difference was observed between the genders except for the length of the NPC, which was greater in males. This finding partially confirmed the hypothesis of the study. Moreover, this result was in line with that of previous studies (Etoz \& Sisman, 2014; Fernández-Alonso, et al., 2014; Friedrich, et al., 2015; Jain, et al., 2017; Mraiwa, et al., 2004; Özçakır-Tomruk, et al., 2016; Thakur, et al., 2013) and can be justified by the fact that males have larger facial dimensions (Thakur, et al., 2013).

Age partially influenced the dimensions of the NPC, so the null hypothesis was partially rejected. Age did not influence the length of the NPC, which corroborates the results of previous studies (Acar \& Kamburoğlu 2014; Etoz \& Sisman, 2014, Fernández-Alonso, et al., 2014; Özçakır-Tomruk, et al., 2016). However, this finding differs from the results of other studies (Bornstein et al., 2011; Jain et al., 2017) that included edentulous patients. These patients may have presented greater bone resorption and consequent remodeling of the surrounding anatomical structures that occurred due to the loss of one or both of the MCI (Bornstein, et al., 2011; Jain, et al., 2017). The inclusion of CBCT images in which the two MCI were present is justified because it facilitates an evaluation of the possible endodontic, surgical, and orthodontic implications of the proximity of these teeth to the NPC.

Additionally, tooth 11 and tooth 21 presented longer lengths among males and in the age group from 18 to 39 years. This evaluation was not performed in previous studies that described the dimensions of the NPC (Acar \& Kamburoğlu 2014; Bornstein, et al., 2011; Etoz \& Sisman, 2014; Fernández-Alonso, et al., 2014; Jain, et al., 2017; Özçakır-Tomruk, et al., 2016).

The relationship between the MCI and NPC has various clinical applications. In dental implant surgeries, this relationship is directly associated with the primary stability of the implants, whose engagement begins around the area previously occupied by half the root length of the MCI. However, few studies exist on this topic (Chatriyanuyoke, et al., 2012; Friedrich, et al., 2015). In implantology, contact of the implant with the neural tissue of the NPC may interfere with osseointegration or result in damage to the nasopalatine nerve (Bornstein, et al., 2011), particularly in cases in which anterior bone resorption is present (Fernández-Alonso, et al., 2015). The mean distances between the root apex of the MCI and the NPC were $2.82 \mathrm{~mm}$ and $2.56 \mathrm{~mm}$ for tooth 11 and tooth 21 , respectively, and the females and young adults presented the lowest mean values. This finding was not confirmed in a study by Chatriyanuyoke et al. (2012), in which higher mean values for the distances between half the root length and the root apexes of the MCI to the NPC were reported. Such differences can be explained by the sample size which, in the present study, was approximately three times larger.

Apical osteolysis greater than $5 \mathrm{~mm}$ increases the probability that the apical lesion will merge with the NPC (Suter, et al., 2016). By extrapolating this consideration to the proximity between the root apex and the NPC presented in the present study, it can be inferred that osteolysis greater than $3 \mathrm{~mm}$ could trigger effects in the NPC. Moreover, there is the possibility of an endodontic pathological process involving the NPC and vice versa. Inflammatory lesions of endodontic origin in the MCI or trauma in the anterior region of the maxilla may stimulate the contents of the NPC to proliferate, forming the NPDC (Mardinger et al., 2008) as well as non-endodontic pathological processes that cause bone expansion. Consequently, this may compromise the vitality of adjacent teeth due to pressure (Ricucci, et al., 2020b). 
The length of the NPC and the diameter of the IF and FS have been determined through an analysis of images in the sagittal reconstruction (Acar \& Kamburoğlu, 2014; Bornstein et al., 2011; Etoz \& Sisman, 2014; Fernández-Alonso, et al., 2014; Jain, et al., 2017; Özçakır-Tomruk, et al., 2016) and the coronal reconstruction (Fernández-Alonso, et al., 2015; Panjnoush, et al., 2016). The best representation of the long axis of the NPC was obtained using the coronal reconstruction, emphasizing that a correction of this reconstruction was made from the sagittal reconstruction while maintaining an equal distance between the walls of the NPC (to define the cut that best represented the long axis of the NPC). This change facilitated a three-dimensional fact analysis because it used the three planes that constituted the multiplanar reconstructions. Additionally, the mean diameter of the NPC was measured because diameters larger than $10 \mathrm{~mm}$ may be indicative of pathological processes within the NPC (Mraiwa, et al., 2004).

Age influenced the morphology of the NPC. The funnel shape was the most prevalent in the 60 to 74 years and 40 to 59 years age groups, while in the younger participants (18 to 39 years), the cylindrical shape was the most common. This suggests an anatomical change throughout life due to physiological and pathological aspects. Most of the participants in this study presented one followed by two SF, as demonstrated in a previous study (Etoz \& Sisman, 2014). However, other studies (Thakur, et al., 2013; Fernández-Alonso, et al., 2014; Jain, et al., 2017) showed that most participants had two SF. This variability reflects the bone formation of this region because it is the junction of various jaw bones (Song, et al., 2009); the presence of foramine and accessory canals should be considered during surgical procedures to avoid nerve injuries (Mraiwa, et al., 2004).

CBCT is an essential tool to assist in the diagnosis and planning of complex or dubious cases (Patel, et al., 2019); its three-dimensional image facilitates an evaluation of the morphology of the NPC, its variability, and its relationship with adjacent anatomical structures. This prevents misdiagnosis of apical pathological processes of endodontic origin (Ricucci, et al., 2020b; Suter, et al., 2011; Vieira, et al., 2020) and contributes to the differentiation of endodontic pathological processes from non-odontogenic processes in early states (Suter, et al., 2011) and surgical planning in cases involving more advanced stages, in which the definitive diagnosis will be histopathological (Ricucci, et al., 2020a).

In this context, we highlight the need for surgical planning for apicectomy and/or implants and for clinical examinations and detailed diagnoses that are supported by conventional radiographs, individualized from lesions in the jaws. Furthermore, we highlight the need for three-dimensional evaluation (Patel, et al., 2019) through CBCT in cases of greater complexity, such as the detection of osteolytic lesions in the periapical region with an inconclusive diagnosis, extensive periapical lesions, and an evaluation of the proximity to relevant anatomical structures. Moreover, one must respect the anatomical variations of each patient, particularly regarding young individuals and females since the measurements tend to be smaller and, therefore, the structures are anatomically closer.

\section{Conclusion}

There was variability in the dimensions of the NPC and its relationship with the MCI, which can be influenced by gender and age. A CBCT scan is relevant for assessing this variability. Although it is not included in a routine examination, it is essential for the diagnosis and planning of dental procedures in the anterior region of the maxilla.

\section{References}

Acar, B., \& Kamburoğlu K. (2015). Morphological and volumetric evaluation of the nasopalatinal canal in a Turkish population using cone-beam computed tomography. Surgical and Radiologic Anatomy, 37(3), 259-265. https://doi.org/10.1007/s00276-014-1348-9.

Asaumi, R., Kawai, T., Sato, I., Yoshida, S., \& Youse, T. (2010). Three-dimensional observation of the incisive canal and the surrounding bone using conebeam computed tomography. Oral Radiology, 26, 20-28. 
Bornstein, M. M., Balsiger, R., Sendi, P., \& von Arx, T. (2011). Morphology of the nasopalatine canal and dental implant surgery: a radiographic analysis of 100 consecutive patients using limited cone-beam computed tomography. Clinical Oral Implants Research, 22(3), 295-301. https://doi.org/10.1111/j.16000501.2010.02010.x.

Chatriyanuyoke, P., Lu, C. I., Suzuki, Y., Lozada, J. L., Rungcharassaeng, K., Kan, J. Y., \& Goodacre, C. J. (2012). Nasopalatine canal position relative to the maxillary central incisors: a cone beam computed tomography assessment. The Journal of Oral Implantology, 38(6), 713-717. doi: 10.1563/AAID-JOI-D-1000106.

Creasy, J. E., Mines, P., \& Sweet, M. (2009). Surgical trends among endodontists: the results of a web-based survey. Journal of Endodontics, 35(1), 30-34. https://doi.org/10.1016/j.joen.2008.10.008.

Etoz, M., \& Sisman, Y. (2014). Evaluation of the nasopalatine canal and variations with cone-beam computed tomography. Surgical and Radiologic Anatomy, 36(8), 805-812. https://doi.org/10.1007/s00276-014-1259-9.

Fernández-Alonso, A., Suárez-Quintanilla, J. A., Muinelo-Lorenzo, J., Bornstein, M. M., Blanco-Carrión, A., \& Suárez-Cunqueiro, M. M. (2014). Threedimensional study of nasopalatine canal morphology: a descriptive retrospective analysis using cone-beam computed tomography. Surgical and Radiologic Anatomy, 36(9), 895-905. https://doi.org/10.1007/s00276-014-1297-3.

Fernández-Alonso, A., Suárez-Quintanilla, J. A., Rapado-González, O., \& Suárez-Cunqueiro, M. M. (2015). Morphometric differences of nasopalatine canal based on 3D classifications: descriptive analysis on CBCT. Surgical and Radiologic Anatomy, 37(7), 825-833. https://doi.org/10.1007/s00276-015-1470-3.

Friedrich, R. E., Laumann, F, Zrnc, T., \& Assaf, A. T. (2015). The nasopalatine canal in adults on cone beam computed tomograms - A clinical study and review of the literature. In Vivo, 29(4), 467-486.

Jain, N. V., Gharatkar, A. A., Parekh, B. A., Musani, S. I., \& Shah, U. D. (2017). Three-dimensional analysis of the anatomical characteristics and dimensions of the nasopalatine canal using cone beam computed tomography. Journal of Maxillofacial and Oral Surgery, 16(2):197-204. https://doi.org/10.1007/s12663016-0879-5.

Kim, Y. T., Lee, J. H., \& Jeong, S. N. (2020). Three-dimensional observations of the incisive foramen on cone-beam computed tomography image analysis. Journal of Periodontal \& Implant Science, 50(1), 48-55. https://doi.org/10.5051/jpis.2020.50.1.48.

Lo Muzio, L., Mascitti, M., Santarelli, A., Rubini, C., Bambini, F., Procaccini, M., Bertossi, D., Albanese, M., Bondì, V., \& Nocini, P. F. (2017). Cystic lesions of the jaws: a retrospective clinicopathologic study of 2030 cases. Oral Surgery, Oral Medicine, Oral Pathology and Oral Radiology, 124(2), 128-138. https://doi.org/10.1016/j.oooo.2017.04.006.

Mardinger, O., Namani-Sadan, N., Chaushu, G., \& Schwartz-Arad, D. (2008). Morphologic changes of the nasopalatine canal related to dental implantation: a radiologic study in different degrees of absorbed maxillae. Journal of Periodontology, 79(9), 1659-1662. https://doi.org/ 10.1902/jop.2008.080043.

Mraiwa, N., Jacobs, R., Van Cleynenbreugel, J., Sanderink, G., Schutyser, F., Suetens, P., van Steenberghe, D., \& Quirynen, M. (2004). The nasopalatine canal revisited using 2D and 3D CT imaging. Dentomaxillofacial Radiology, 33(6), 396-402. https://doi.org/10.1259/dmfr/53801969.

Özçakır-Tomruk, C., Dölekoğlu, S., Özkurt-Kayahan, Z., \& İlgüy, D. (2016). Evaluation of morphology of the nasopalatine canal using cone-beam computed tomography in a subgroup of Turkish adult population. Surgical and Radiologic Anatomy, 38(1), 65-70. https://doi.org/10.1007/s00276-015-1520-x.

Panjnoush, M., Norouzi, H., Kheirandish, Y., Shamshiri, A. R., \& Mofidi, N. (2016). Evaluation of morphology and anatomical measurement of nasopalatine canal using cone beam computed tomography. Journal of Dentistry (Tehran, Iran), 13(4), $287-294$.

Patel, S., Brown, J., Semper, M., Abella, F., \& Mannocci, F. (2019). European Society of Endodontology position statement: Use of cone beam computed tomography in Endodontics: European Society of Endodontology (ESE) developed by. International Endodontic Journal, 52(12), 1675-1678. https://doi.org/10.1111/iej.13187.

Ricucci, D., Amantea, M., Girone, C., Feldman, C., Rôças, I. N., \& Siqueira Jr, J. F. (2020a). An unusual case of a large periapical cyst mimicking a nasopalatine duct cyst. Journal of Endodontics, 46(8),1155-1162. https://doi.org/10.1016/j.joen.2020.04.013.

Ricucci, D., Amantea, M., Girone, C., \& Siqueira Jr, J. F. (2020b). Atypically grown large periradicular cyst affecting adjacent teeth and leading to confounding diagnosis of non-endodontic pathology. Australian Endodontic Journal, 46(2), 272-281. https://doi.org/10.1111/aej.12381.

Song, W. C., Jo, D. I., Lee, J. Y., Kim, J. N., Hur, M. S., Hu, K. S., Kim, H. J., Shin, C., \& Koh, K. S. (2009). Microanatomy of the incisive canal using threedimensional reconstruction of microCT images: an ex vivo study. Oral Surgery, Oral Medicine, Oral Pathology, Oral Radiology, and Endodontics, 108(4), 583-590. https://doi.org/10.1016/j.tripleo.2009.06.036.

Suter, V. G., Büttner, M., Altermatt, H. J., Reichart, P. A., \& Bornstein, M. M. (2011). Expansive nasopalatine duct cysts with nasal involvement mimicking apical lesions of endodontic origin: a report of two cases. Journal of Endodontics, 37(9), 1320-1326. https://doi.org/10.1016/j.joen.2011.05.041.

Suter, V. G., Jacobs, R., Brücker, M. R., Furher, A., Frank, J., von Arx, T., \& Bornstein, M. M. (2016). Evaluation of a possible association between a history of dentoalveolar injury and the shape and size of the nasopalatine canal. Clinical Oral Investigation, 20(3):553-561. https://doi.org/10.1007/s00784-015-15487 .

Thakur, A. R., Burde, K., Guttal, K., \& Naikmasur, V. G. (2013). Anatomy and morphology of the nasopalatine canal using cone-beam computed tomography. Imaging Science in Dentistry, 43(4), 273-281. https://doi.org/10.5624/isd.2013.43.4.273.

Tsuneki, M., Maruyama, S., Yamazaki, M., Abé, T., Adeola, H. A., Cheng, J., Nishiyama, H., Hayashi, T., Kobayashi, T., Takagi, R., Funayama, A., Saito, C., \& Saku, T. (2013). Inflammatory histopathogenesis of nasopalatine duct cyst: a clinicopathological study of 41 cases. Oral Diseases, 19(4), 415-424. https://doi.org/10.1111/odi.12022.

Vieira, C. C., Pappen, F. G., Kirschnick, L. B., Cademartori, M. G., Nóbrega, K. H. S., do Couto, A. M., Schuch, L. F., Melo, L. A., dos Santos, J. N., de Aguiar, M. C. F., \& Vasconcelos, A. C. U. (2020). A retrospective Brazilian multicenter study of biopsies at the periapical area: identification of cases of nonendodontic periapical lesions. Journal of Endodontics, 46(4), 490-495. https://doi.org/10.1016/j.joen.2020.01.003. 